\title{
CRITERIOS PARA LA IDENTIFICACIÓN Y SELECCIÓN DE PAISAJES ESPAÑOLES SUSCEPTIBLES DE SER INCLUIDOS EN LA LISTA DEL PATRIMONIO MUNDIAL DE UNESCO ${ }^{1}$
}

\author{
Víctor Fernández Salinas \\ Rocío Silva Pérez \\ Departamento de Geografía Humana. Universidad de Sevilla \\ salinas@.us.es, rsilva@us.es
}

\section{RESUMEN}

La Lista del Patrimonio Mundial de Unesco, además del más alto reconocimiento patrimonial internacional, convierte a sus bienes en un referente de protección y gestión. Los paisajes culturales son una categoría relativamente reciente en la Lista. Este artículo propone una serie de paisajes que, por sus valores, los criterios de Unesco y las características del proceso de incorporación de bienes españoles a la Lista, podría aumentar el número de paisajes culturales españoles y, con ello, un mayor aprecio, sensibilización y estrategias de protección y gestión al conjunto de los paisajes patrimoniales.

Palabras clave: Patrimonio, paisajes culturales, paisajes patrimoniales, Patrimonio Mundial de Unesco.

\section{ABSTRACT}

The World Heritage List of the Unesco, more than the highest international heritage recognition, makes its properties a reference for protection and management. Cultural landscapes are a relatively new category in the List. This article proposes a group of landscapes which, by their values, the Unesco criteria and the Spanish particular way of incorporation

Fecha de recepción: abril 2013.

Fecha de aceptación: enero 2014.

1 Este artículo se inserta en el Proyecto de Investigación del Ministerio de Economía y Competitividad Paisajes Patrimoniales de la España Meridional Andaluza (Referencia: CSO2012-39564-C07-07). 
to the List, could increase the number of Spanish cultural landscapes and, thus, a greater appreciation, awareness and strategies for protection and management to the whole of the heritage landscapes.

Keywords: Heritage, cultural landscapes, heritage landscapes, World Heritage of Unesco.

\section{INTRODUCCIÓN}

Hace ya varios decenios que los agentes sociales, económicos y gubernamentales que operan en los territorios muestran un creciente interés por el reconocimiento institucional de los bienes patrimoniales en ellos existentes. Esto responde a su valoración cultural, pero también a una estrategia de marketing y visibilidad espacial, a menudo enmarcada en programas de desarrollo territorial para los que los bienes patrimoniales -como recursos específicos y no deslocalizables- son considerados activos competitivos básicos. La globalización, la ampliación de flujos y el aumento de la competitividad entre territorios elevan actualmente la importancia de las distinciones internacionales, sobre todo las de Unesco a través del Programa MaB y, más aún, de la Convención para la Protección del Patrimonio Mundial Natural y Cultural (en adelante, Convención), de la que deriva la Lista del Patrimonio Mundial (en adelante, Lista).

Paralela a este proceso se produce en los últimos decenios una mayor complejidad del concepto de patrimonio que, por un lado, cede el protagonismo del objeto (la materialidad del bien), al sujeto (la sociedad que crea y disfruta ese bien). También ha cambiado la consideración espacial de los recursos culturales. Hasta los años setenta del siglo XX los centros históricos eran el ámbito más generoso en el que se entendían las interrelaciones entre patrimonio cultural y sociedad. En los últimos decenios del siglo pasado y, sobre todo, en los primeros años del nuevo, la perspectiva espacial se amplía a contextos espaciales más extensos y adquieren mayor relevancia bienes culturales que, si bien apreciados, tenían escasa cabida en el marco conceptual y de gestión tradicionales. La emergencia del territorio como elemento básico en el que entender el patrimonio (tanto como escenario, pero también como actor) alienta nuevas formas de entender, en general, los recursos culturales y, en particular, aquellos intrínsecamente ligados a territorios que trascienden la escala local para enmarcarse, al menos, en la comarcal. Es el momento en el que comienzan a valorarse la arqueología industrial y de la obra pública, los paisajes patrimoniales (más conocidos como culturales, ver más adelante) o los itinerarios culturales.

Este trabajo se interesa por los paisajes patrimoniales ${ }^{2}$, pero especialmente aquellos que forman parte de la Lista; éstos son paisajes que poseen un reconocimiento internacional basado en criterios científicamente probados y, sobre todo, que son incluidos en ese inventario para que su gestión sirva de referente a otros paisajes con características similares. La intención de Unesco no es hacer un registro de los mejores bienes inmuebles del planeta, sino establecer un elenco de ejemplos representativos en el que los responsables de la gestión patrimonial encuentren criterios para identificar mejor sus bienes y encarar su reconocimiento, protección y provecho.

2 En este trabajo se utiliza la expresión «paisaje patrimonial» al referirse a cualquier paisaje que deba ser protegido en razón de sus valores naturales y/o culturales. La expresión paisaje cultural -en cursiva- se utilizará únicamente cuando se trate de esta categoría específica utilizada por Unesco. 
España es un país con una gran calidad de paisajes (no sólo de los patrimoniales), pero que, tanto por su modelo de desarrollo, como por la baja sensibilidad y escaso conocimiento de sus valores, ha visto muy afectados entornos paisajísticos de gran calidad. La crisis actual es un momento crucial para plantear nuevas estrategias de paisaje, de las que ya hay iniciativas, que supongan un punto de inflexión en relación con su consideración social. En esta línea, el camino ha de ser de doble sentido: las acciones deben venir de arriba abajo (de las administraciones a la sociedad civil) y viceversa.

Incluirse en la Lista es un objetivo al que aspiran muchas ciudades y territorios. España es el segundo país por su número de bienes en ella. En el interés por ser integrado en la Lista suelen coincidir tanto los anhelos locales como los centrales; y esto no es baladí dadas las numerosas reticencias y conflictos locales que se derivan de muchas declaraciones patrimoniales (tanto naturales -parques, reservas...-, como culturales -conjuntos históricos, zonas arqueológicas...-), poco o mal entendidas por las autoridades municipales y población en general, que ven en estas declaraciones más una cortapisa que un recurso para el desarrollo; bien es cierto que se percibe un cambio de actitud, especialmente en territorios con grupos de desarrollo local conscientes de la importancia de sus recursos y del reconocimiento que éstos posean. No obstante, todavía se puede afirmar que de abajo arriba hay un notable recelo en las declaraciones patrimoniales.

Ahora bien, si la inclusión en la Lista constituye un campo de encuentro de las actitudes centrales y las locales, la integración de bienes españoles es cada vez más difícil, y no sólo por tener ya una buena cantidad de bienes reconocidos, sino porque hay otros aspectos que conciernen a la política de Unesco, y que serán detallados más adelante, que no favorecen el reconocimiento de nuevos bienes españoles.

En razón de todo esto, los objetivos centrales de este artículo son:

- Reflexionar sobre la forma en que la Lista puede ser una herramienta para un mejor reconocimiento institucional y social de los paisajes patrimoniales españoles en general, y no sólo de los incluidos en ella.

- Proporcionar claves para la identificación y selección de paisajes patrimoniales españoles con posibilidades de ser incluidos en la Lista.

Como objetivos secundarios, se proponen:

- Reflexionar sobre el concepto de paisajes patrimoniales y sus categorías.

- Analizar la política actual de Unesco respecto a la Lista y la manera en que ésta puede afectar a las candidaturas españolas.

- Valorar la dimensión espacial de los bienes patrimoniales españoles con reconocimiento institucional.

- Revisar la experiencia española relacionada con la Lista desde la perspectiva del Estado y de las comunidades autónomas.

- Aportar un listado, ni exhaustivo ni definitivo, respecto a paisajes españoles susceptibles de ser considerados paisajes culturales en la Lista del Patrimonio Mundial de Unesco.

Respecto a los objetivos señalados y al método para alcanzarlos, es importante señalar que este trabajo no pretende identificar todos los paisajes patrimoniales españoles susceptibles de integrar la Lista; labor que debe plantearse desde los territorios y el Estado. También es preciso reseñar que los autores de este artículo no creen que aumentar la presencia de bienes en la Lista sea en sí una acción positiva o deseable, ni siquiera que esto asegure su completa protección; la experiencia muestra muchas excepciones al respecto. Sí se cree, en 
cambio, que el reconocimiento de paisajes españoles como paisajes culturales de la Lista redundará en una mayor atención política y técnica a la protección del paisaje y en una mayor sensibilidad social respecto a sus valores. Esta línea es la que orienta este artículo y no la del simple apoyo al incremento y consagración de unos bienes culturales que son igual de importantes estén, o no, en la Lista de Unesco.

Para alcanzar los objetivos señalados, y dada la polisemia y ambigüedad de los conceptos de patrimonio y de paisaje, se acomete inicialmente una reflexión taxonómica. A continuación, se analiza el reconocimiento del patrimonio, en general, y de los paisajes culturales, en particular, por parte de Unesco; abundando en las prioridades de esta institución para inscribir bienes en la Lista. Establecido el marco general, se presenta una valoración del territorio español en relación con la dimensión paisajística de sus bienes naturales y culturales reconocidos; para, a continuación, centrar el análisis en la presencia española en la Lista y en el procedimiento y perspectivas de nuevas inscripciones aprovechando las posibilidades que ofrece la figura de paisaje cultural. Con ello se ofrece una visión objetiva de las potencialidades de España para realizar nuevas o mejores nominaciones a Unesco. Esto se concreta en una propuesta abierta y no exhaustiva de paisajes patrimoniales españoles susceptibles de integrar la Lista de Unesco con valor representativo y cuya gestión pudiera servir en los años venideros de referente al resto.

Entre las fuentes más útiles para el desarrollo de este trabajo hay que destacar los recursos digitales del Centro del Patrimonio Mundial de Unesco (www.whc.org). De gran utilidad también han sido los abundantes trabajos del Comité Internacional de Monumentos y Sitios (Icomos), muchos de ellos disponibles en su página web (www.icomos.org). La Unión Internacional para la Conservación de la Naturaleza (www.iucn.org) también dispone de numerosos trabajos sobre paisajes, algunos de los cuales han sido utilizados en este artículo. El elenco de monografías y otros trabajos revisados se reseña al final.

\section{LOS PAISAJES DESDE LA PERSPECTIVA PATRIMONIAL}

\section{II.1. Paisajes patrimoniales, paisajes culturales}

Los paisajes, en cuanto herencia territorial resultado de la apropiación del espacio por la sociedad que los ha modelado y se identifica en ellos, son en sí mismos bienes culturales. La dimensión patrimonial del paisaje adquiere un especial significado en el contexto actual de hibridación, banalización y pérdida de autenticidad de muchos de ellos. El Convenio Europeo del Paisaje señala en su preámbulo que el paisaje «es un componente fundamental del patrimonio natural y cultural europeo, que contribuye al bienestar de los seres humanos y a la consolidación de la identidad europea» (Consejo de Europa, 2000). Si el paisaje es un condensador de identidad territorial y, por lo tanto, patrimonio cultural, cabe preguntarse qué añaden los adjetivos cultural y patrimonial a una realidad que es intrínsecamente cultura y patrimonio. La respuesta debe enmarcarse en la propia evolución de los conceptos de patrimonio (cultural y/o natural) y de paisaje. Hasta hace poco el concepto de patrimonio se circunscribía al patrimonio histórico, al tiempo que los bienes naturales eran considerados otro tipo de riqueza merecedora de protección, pero sin gran conexión conceptual con el primero. Por su parte, la noción de patrimonio histórico, restringida hasta bien avanzado el siglo XX a hitos monumentales de carácter emblemático y de preferente localización urbana, se ha ampliado hasta abarcar 
elementos modestos y cotidianos, ámbitos territoriales más extensos y complejos, y paisajes (Castillo, 2009). A su vez, los bienes naturales se patrimonializan y se confunden con los culturales, hasta el punto de que todo patrimonio, en cuanto implica apropiación y asignación social de valores, está mediatizado por la cultura y es patrimonio cultural, con independencia de que el bien sea natural o construcción humana. La diferencia entre patrimonio natural y cultural es una cuestión de carácter operativo para diferenciar bienes con una dominante u otra, pero que, conceptualmente, proceden de un mismo hecho: el reconocimiento de valores singulares e identitarios. Proteger el parque nacional de Garajonay, por ejemplo, se explica por el interés de nuestra cultura en defender los recursos de espacios poco antropizados y con valores científiconaturales; así, este parque es, antes que otra cosa, producto de una expresión cultural.

Por una cuestión de coherencia conceptual, se niega la existencia de paisajes naturales. El concepto de paisaje implica siempre mirada humana; es decir, la imagen procesada por un cerebro influido por claves culturales; incluso aunque esta mirada se dirija a un espacio natural no intervenido. Así, hablar de paisaje natural es una incongruencia, lo mismo que decir paisaje cultural es una redundancia. En todo caso, podría hablarse de paisajes de dominante natural o cultural en razón del protagonismo y carácter de los elementos y atributos que los conforman.

Los primeros documentos de protección de paisajes los identifican como espacios excelsos y de reconocido valor (natural y/o cultural). Ésta es la acepción que emana de las declaraciones de los parques nacionales estadounidenses en la segunda mitad del siglo XIX y primeros decenios del XX; o de algunos textos de Unesco, como la Recomendación relativa a la protección de la belleza y el carácter de los lugares de 1962, cuya protección implica «la preservación y, cuando sea posible, la restitución del aspecto de los lugares y paisajes naturales, rurales o urbanos debidos a la naturaleza o a la mano del hombre que ofrecen un interés cultural o estético o que constituyen medios naturales característicos» (Unesco, en línea, original de 1962).

El citado Convenio Europeo del Paisaje señala que todo territorio tiene interés como paisaje y que éste concierne «tanto a los paisajes que puedan considerarse excepcionales como a los paisajes cotidianos o degradados» $\left(\operatorname{art}^{\circ} 2\right)$; pero que el paisaje sea todo el territorio y que el concepto de paisaje tenga un calado cultural no implica que todos los paisajes sean paisajes patrimoniales. Esta categoría debe circunscribirse a aquellos paisajes que por su singularidad y/o representatividad merezcan ser objeto de reconocimiento y tutela. El convenio establece como aspectos básicos a considerar la protección, gestión y ordenación de los paisajes. Si todos ellos deben ser gestionados y una parte debe ser ordenada, aquellos que posean valores singulares requerirán salvaguardia y tutela administrativa ${ }^{3}$. Estos últimos son los paisajes que merecen el calificativo de paisajes patrimoniales. Se trata de unidades territoriales complejas, cuyo carácter va mucho más allá de la identificación de piezas aisladas de valor cultural (castillos, monasterios, molinos, puentes, martinetes...), por mucho que algunos de ellos denoten con fuerza el paisaje. Tampoco se pueden referir únicamente a ejes de comunicación (caminos históricos o itinerarios culturales), y ni siquiera sólo a la proyección espacial de actividades económicas más o menos extensivas

3 «Por 'protección de los paisajes' se entenderán las acciones encaminadas a conservar y mantener los aspectos significativos o característicos de un paisaje, justificados por su valor patrimonial derivado de su configuración natural y/o la acción del hombre», Convenio Europeo del Paisaje, art. $1^{\circ}$, pto. D. 
(huertas, bancales, enclaves mineros...). Tales elementos, a los que habría que añadir otros de carácter inmaterial y simbólico (que a menudo son las verdaderas esencias de un paisaje), pueden actuar como vectores de patrimonialización. Éstos vectores constituyen realidades -visibles o no- y procesos a partir de los cuales se construye el reconocimiento patrimonial; no obstante, y abundando en lo que antes se señalaba, estos vectores, aun con su importancia cultural, no son en sí mismos paisajes patrimoniales. El paisaje patrimonial es el resultado de lo que podría dar en llamarse el argumento y el carácter territorial; y éstos se estructuran a partir de la interacción de vectores patrimoniales, como los citados, con el resto de los componentes del territorio que no poseen valores identitarios y/o no tienen reconocimiento institucional de sus valores culturales. Territorio, patrimonio y paisaje son pues un trinomio fundamental para entender la identificación y protección de los valores de los paisajes patrimoniales.

La literatura sobre paisajes patrimoniales ha producido un amplio grupo de términos y figuras de protección que se imbrican y superponen. Sólo en España ${ }^{4}$ podrían citarse: paisajes de interés cultural, lugares de excepcional valor paisajístico, paisajes singulares, paisajes sobresalientes, etcétera. Entre ellas, la que mayor predicamento ha tenido es la de paisaje cultural, que es la utilizada por Unesco, aunque no es la denominación más acertada conceptualmente, dado que, como se ha dicho, todos los paisajes son culturales.

La identificación de paisajes patrimoniales tiene ya cierto recorrido. La concepción tradicional de los paisajes como espacios poco transformados y de amplias panorámicas (Maderuelo, 2005) centró el interés inicial en los espacios naturales y áreas rurales. Un especial significado tienen los trabajos desarrollados a partir de The Permanent European Conference for the Study of the Rural Landscape (PECSRL), que se publican desde 1957 coincidiendo con sus congresos (PECSRL, 2010); el de 2008, sobre «Landscapes, Identities and Development», tiene gran relevancia pues reconoce el paisaje como motor de identidad y desarrollo territorial (Mata Olmo, 2008). Paisajes especialmente analizados, por sus cualidades estéticas y sus elevados valores sociales e históricos, son los paisajes del bocage (Oreszczyn y Lane, 2000) y los paisajes del viñedo (Briffaud, s. et Brochot, 2010). En el caso español, destacan los paisajes de la dehesa (Silva Pérez, 2010) y los regadíos tradicionales e históricos (Hermosilla, ed., 2010; Mata Olmo y Fernández, 2010).

También debe citarse la relación entre ciudad histórica y paisaje, de la que se observa una continuidad en la producción científica, al menos, desde las propuestas urbanísticas de Cami1lo Sitte que identificaba el confort urbano con determinados tipos de escenarios (1965; ed. original de 1889). Pero es en los últimos decenios cuando esta relación adquiere mayor relevancia, sobre todo desde que entra en crisis el concepto de conjunto histórico como marco suficiente para proteger la imagen histórica de la ciudad y se acude a fórmulas espacialmente más generosas y complejas en el espacio urbano. Desbordaría el objetivo de este trabajo realizar una revisión de esta producción científica, pero baste señalar que atiende tanto a la mejor integración en el paisaje de los centros históricos (Venegas Moreno y Rodríguez

4 En España se produce un temprano reconocimiento de este tipo de paisajes, pues el Instituto Nacional para la Conservación de la Naturaleza (Icona) realizó un Inventario de paisajes sobresalientes en 1975 que ha servido de base para el reconocimiento de un buen número de paisajes por parte de las comunidades autónomas. 
Rodríguez, 2002), como a la dimensión patrimonial general de la ciudad (ver más adelante consideraciones sobre los paisajes urbanos históricos).

Otro aspecto relevante tiene que ver con el propósito del reconocimiento de paisajes patrimoniales. Desde una intención preferentemente estética y conservacionista, se ha pasado a dar cierta prioridad al desarrollo territorial. Ello supone un reforzamiento de las facetas económicas y sociales del paisaje, que lo conciben como el marco de vida, espacio para el disfrute ciudadano y activo para el desarrollo socioeconómico. La expansión global de los mercados turísticos, junto a la emergencia de una mentalidad postmaterialista interesada en la reinterpretación y puesta en valor de activos intangibles como la cultura (Martínez de Pisón, 2003), la calidad de vida (Tuan, 2003) o la estética de los territorios (Riesco, 2003), han creado una demanda de productos y destinos significados por su valor patrimonial. La identificación de paisajes patrimoniales constituye, pues, una oportunidad para la generación de riqueza y empleo de gran interés ante la profunda crisis económica actual que impele a la reactivación de todas las ventajas y potencialidades de los territorios.

También es importante la clasificación de las tipologías de los paisajes patrimoniales. En este sentido, cabe señalar que la utilizada por Unesco, aunque doble, es en exceso simple. Por un lado diferencia entre paisajes culturales con valor sólo cultural y aquellos mixtos -cultural y natural-. A su vez los clasifica en razón de su diseño, evolución o asociación (ver más adelante). De más interés resultan otras clasificaciones, escasas, que parten de una mirada más compleja de los paisajes patrimoniales. Destaca la del Laboratorio de Paisaje del Instituto Andaluz del Patrimonio Histórico (Rodrigo Cámara et al., 2012; tabla 1), cuya metodología ha sido aconsejada por el Instituto Español de Patrimonio Cultural a las comunidades autónomas para hacer sus inventarios de paisajes patrimoniales. Por esta razón, esta clasificación es utilizada como referente de categorización de paisajes patrimoniales en este trabajo.

Tabla 1

CLASIFICACIÓN DE LOS PAISAJES PATRIMONIALES

\begin{tabular}{|c|c|c|}
\hline & Categorías & Tipos \\
\hline \multirow{5}{*}{$\begin{array}{l}\text { Ámbito de } \\
\text { los sistemas } \\
\text { territoriales }\end{array}$} & \multirow{2}{*}{ A. Sistemas de asentamiento } & A.1 Paisajes rurales \\
\hline & & A.2 Paisajes urbanos \\
\hline & \multirow{2}{*}{$\begin{array}{l}\text { B. Sistemas de } \\
\text { infraestructuras territoriales }\end{array}$} & B.1 Paisajes de los transportes y comunicaciones \\
\hline & & B.2 Paisajes relacionados con otras infraestructuras \\
\hline & C. Sistemas defensivos & C.1 Paisajes relacionados con técnica militar \\
\hline \multirow{3}{*}{$\begin{array}{l}\text { Ámbito de } \\
\text { los sistemas } \\
\text { productivos }\end{array}$} & \multirow{3}{*}{ D. Sistemas de producción } & D.1 Paisajes agrarios y pesqueros \\
\hline & & D.2 Paisajes mineros e industriales \\
\hline & & D.3 Paisajes relacionados con las acts. de servicios \\
\hline \multirow{6}{*}{$\begin{array}{l}\text { Ámbito de } \\
\text { los sistemas } \\
\text { de valores } \\
\text { simbólicos }\end{array}$} & \multirow{3}{*}{$\begin{array}{l}\text { E. Sistemas de creencias y } \\
\text { rituales, expresión de poder } \\
\text { y artes }\end{array}$} & E.1 Paisajes relacionados con creencias y rituales \\
\hline & & E.2 Paisajes relacionados con la expresión de poder \\
\hline & & E.3 Paisajes relacionados con la forma artística \\
\hline & \multirow{3}{*}{$\begin{array}{l}\text { F. Sistemas de referentes } \\
\text { naturales connotados }\end{array}$} & F.1 Paisajes relacionados con ríos y lagos \\
\hline & & F.2 Paisajes relacionados con formas del relieve \\
\hline & & F.3 Paisajes relacionados con zonas de tránsito \\
\hline
\end{tabular}

Fuente: adaptado a partir de Cámara Rodrigo, J.M. et al. (2012). 


\section{II.2. Unesco y los paisajes culturales}

\section{II.2.1. La Lista: fundamentos, evolución y prioridades}

La Lista, como ya se ha señalado, es producto de la Convención, aprobada por Unesco en 1972. El objetivo básico de este texto es la corresponsabilidad internacional en la preservación de bienes patrimoniales con valor universal excepcional (ver más adelante) y darles una misión en la sociedad contemporánea en la que se insertan. En 2013 un total de 186 países la han ratificado y los bienes declarados son 962. Se trata, en su mayor parte, de bienes culturales (745) y, en menor medida, de bienes naturales (188) y mixtos (29). Los estados, territorios y lugares que poseen bienes incluidos en la Lista han entendido por norma general esta circunstancia como un reconocimiento que los acreditan entre los mejores ejemplos en sus respectivas categorías (ciudades históricas, monumentos naturales, etcétera). La pertenencia a la Lista se ha asimilado a la obtención de una marca de excelencia y, en consecuencia, de un recurso muy competitivo.

Casi desde el nacimiento de esta Lista, surgen procesos inesperados que influirán notablemente en su desarrollo. Cabe recordar que su andadura empieza a finales de los años setenta, cuando el planeta se encontraba inmerso en un importante proceso de reestructuración socioeconómica; una situación que inevitablemente remite al momento actual. Otros procesos influyentes son: la gran expansión del turismo cultural; la necesidad de mejorar la imagen de ciudades y territorios; y, no menos importante, la complejidad conceptual del patrimonio, que engloba nuevas categorías y da un valor a expresiones culturales cuyo aprecio apenas despuntaba en los años setenta (arqueología industrial y de la obra pública, patrimonio inmaterial...). Unesco, a través del Comité del Patrimonio Mundial, que es el órgano responsable del seguimiento de la Convención y de la Lista, ha intentado encarar estos procesos con diversas estrategias; sobre todo aquellas que han intentado convencer, tanto a los estados como a los actores locales, de que la inclusión en la Lista no es tanto un reconocimiento como una responsabilidad: la de servir de referente de gestión a bienes similares no inscritos. Esto ha obligado a replanteamientos continuos dentro del Comité del Patrimonio Mundial que pueden seguirse a través de las sucesivas guías operativas para la implementación de la Convención (la primera, publicada en 1977, contenía 27 parágrafos, la de 2012, 290; World Heritage Committee, en línea).

El Comité del Patrimonio Mundial lleva años desarrollando propuestas que mantengan la legitimidad científica de la Lista, sobre todo desde la Declaración de Budapest sobre el Patrimonio Mundial de 2002. En ella se establece la Estrategia global para una Lista del Patrimonio Mundial representativa, equilibrada y creíble que cubra lagunas y corrija desajustes entre categorías de bienes inscritos y entre regiones del planeta. Las acciones que prevé esta estrategia son:

a) Establecer listas indicativas, que son elencos de bienes sobre los que los estados parte declaran estar trabajando para proponer su inclusión en la Lista en los años venideros.

b) Conocer los resultados de reuniones regionales y temáticas sobre Patrimonio Mundial que orienten las políticas de la Lista. 
c) Tender hacia el equilibrio entre bienes culturales y naturales.

d) Convencer a los países bien representados en la Lista de que espacien nuevas candidaturas.

e) Limitar a dos las inscripciones anuales por Estado Parte; de ellas sólo una puede ser cultural.

f) Dar prioridad a: bienes en categorías poco representadas; bienes de países sin declaraciones o con pocas; bienes que quedaron excluidos en sesiones anteriores del Comité del Patrimonio Mundial; bienes naturales; bienes de carácter mixto (cultural y natural); bienes transnacionales; bienes pertenecientes a África, Pacífico y Caribe; bienes de países que han ratificado la Convención en los últimos diez años; y bienes de países que no han presentado propuestas de inscripción durante diez o más años.

Para todo lo anterior, Unesco incorpora también nuevos métodos para valorar las candidaturas:

- Se crean nuevas categorías, cuyo reconocimiento viene precedido frecuentemente por la aprobación de cartas internacionales elaboradas o asumidas por Unesco o sus principales instituciones asesoras: el Consejo Internacional de Monumentos y Sitios (Icomos) y la Unión Internacional para la Conservación de la Naturaleza (Uicn).

- Se afina en la determinación del valor universal excepcional, que se liga al carácter singular de los bienes, a su adecuación a los diez criterios señalados por la Convención (tabla 2) y a las circunstancias de autenticidad e integridad que posean.

- Se da máxima importancia a los planes de gestión. Los estados que envíen nuevas candidaturas deben acreditar, no sólo sus valores, sino sus recursos y estrategias para conservarlos.

- Se suceden, tal y como se ha adelantado, las publicaciones y revisiones de la guías operativas para la aplicación de la Convención: pero el proceso acumulativo de disposiciones en estas guías resta una coherencia global y cada vez es más urgente que se realice una revisión completa de la propia Convención que sistematice correctamente, tanto el devenir conceptual del patrimonio, como la propia estructura de la Lista.

- Por último, desde 2002, el Comité del Patrimonio Mundial ha limitado a 45 el máximo de candidaturas que estudia cada año, incluyendo en ellas las propuestas que hubieran sido presentadas y no aceptadas en comités anteriores; sólo se exceptúan las modificaciones menores de límites de bienes que ya están en la Lista.

\section{II.2.2. Los paisajes culturales en la Lista}

Unesco viene trabajando de manera específica en paisajes a partir de los primeros años ochenta, cuando empiezan a apreciarse los valores de los paisajes rurales atribuidos a algunos bienes de la Lista (Fawler, 2003: 66). El desarrollo de ésta evidencia entonces que las categorías establecidas en 1972 para el patrimonio cultural (monumentos, conjuntos y luga- 
res) no se adecuan bien a categorías patrimoniales emergentes que deben ser conceptuadas en escalas territoriales amplias. En 1987 aparecen paisajes en la Lista (Uluru-Kata Tjuta -Australia-; Aranjuez...), aunque aún no estaba reconocida la denominación de paisajes culturales (Luengo Añón y Mechtild, 2012). Ésta se institucionaliza en 1992 y el parque nacional de Tongariro (Nueva Zelanda) es el primer bien inscrito en esta nueva categoría en 1993 y, al año siguiente, la puesta al día de la Guía operativa para la implementación de la Convención incorpora un párrafo específico sobre paisajes culturales ( $\left.\mathrm{n}^{\circ} 39\right)$ : «lugares que combinan el trabajo de la naturaleza y el ser humano, y que son ilustrativos de la evolución de la sociedad humana y del uso del espacio a lo largo del tiempo, bajo la influencia de limitaciones físicas y/o oportunidades presentadas por el medio natural y de sucesivas fuerzas sociales, económicas y culturales».

La clasificación de los paisajes culturales de Unesco se estructura desde entonces en tres tipos:

a) Paisajes definidos, diseñados y creados por el ser humano.

b) Paisajes evolutivos; que a su vez se diferencian entre fósiles/relictos y continuos.

c) Paisajes asociativos.

Esta clasificación contiene un amplio espectro de paisajes: desde aquellos en los que los atributos que los denotan -o sea, que los describen objetivamente- son fundamentales (categoría «a») hasta los que basan sus valores en atributos que los connotan -es decir, que les asignan significados subjetivos (categoría «c»); la categoría intermedia («b») participa a la vez de atributos denotados y connotados. Sin embargo, hay que tener en cuenta que estas categorías son más conceptuales que funcionales (Fawler, 2003), por lo que, como se ha indicado, no es una clasificación muy operativa para un reconocimiento ajustado de los valores patrimoniales que poseen los paisajes.

Respecto al número de paisajes culturales inscritos a partir de 1993, se aprecia una tendencia al alza, si bien no continua, y en ella alternan años con más de siete candidaturas aceptadas, frente a otros en los que el número de éstas es más bien contenido (menos de cuatro). Desde la última incorporación de paisajes culturales a la Lista (agosto de 2012), hay 81 bienes inscritos como tales; cuatro de ellos transnacionales. Una gran mayoría tiene carácter cultural (75), frente a una minoría de carácter mixto (6). Los paisajes más abundantes son los evolutivos (66: 27 fósiles y 39 continuos), seguidos de los creados intencionadamente por el ser humano (12). Los asociativos son los menos abundantes (3), pero debe tenerse en cuenta que la dimensión simbólica está casi siempre presente en todos ellos, con lo que no se puede decir que no se atienda a esta dimensión del paisaje.

La tabla 2 presenta los criterios utilizados por Unesco para la determinación, entre otros aspectos, del valor universal excepcional de un bien y su frecuencia en las declaraciones de paisajes culturales. Los más repetidos son el III y el IV; aquellos sustentados en la existencia de testimonios de tradiciones culturales, vivas o no, y/o que ilustran una etapa histórica significativa. En cambio, los criterios relacionados con la creatividad humana (I) o con los valores naturales (VII al X) muestran una presencia menor. 
Tabla 2

FRECUENCIA DE LOS CRITERIOS EN LAS DECLARACIONES DE BIENES EN LA LISTA DEL PATRIMONIO MUNDIAL COMO PAISAJES CULTURALES

\begin{tabular}{|l|c|}
\hline Criterios & Frecuencia \\
\hline I. Representar una obra maestra del genio creativo humano. & $\mathbf{5}$ \\
\hline $\begin{array}{l}\text { II. Testimoniar un importante intercambio de valores humanos a lo largo de un periodo de } \\
\text { tiempo o dentro de un área cultural del mundo, en el desarrollo de la arquitectura o tecnología, } \\
\text { artes monumentales, urbanismo o diseño paisajístico. }\end{array}$ & $\mathbf{2 7}$ \\
\hline $\begin{array}{l}\text { III. Aportar un testimonio único o al menos excepcional de una tradición cultural o de una } \\
\text { civilización existente o ya desaparecida. }\end{array}$ & $\mathbf{5 1}$ \\
\hline $\begin{array}{l}\text { IV. Ofrecer un ejemplo eminente de un tipo de edificio, conjunto arquitectónico o tecnológico o } \\
\text { paisaje, que ilustre una etapa significativa de la historia humana. }\end{array}$ & $\mathbf{4 8}$ \\
\hline $\begin{array}{l}\text { V. Ser un ejemplo eminente de una tradición de asentamiento humano, utilización del mar o de } \\
\text { la tierra, que sea representativa de una cultura (o culturas), o de la interacción humana con el } \\
\text { medio ambiente especialmente cuando éste se vuelva vulnerable frente al impacto de cambios } \\
\text { irreversibles. }\end{array}$ & $\mathbf{3 9}$ \\
\hline $\begin{array}{l}\text { VI. Estar directa o tangiblemente asociado con eventos o tradiciones vivas, con ideas, o con } \\
\text { creencias, con trabajos artísticos y literarios de destacada significación universal. (El comité } \\
\text { considera que este criterio debe estar preferentemente acompañado de otros criterios). }\end{array}$ & $\mathbf{2 8}$ \\
\hline $\begin{array}{l}\text { VII. Contener fenómenos naturales superlativos o áreas de excepcional belleza natural e } \\
\text { importancia estética. }\end{array}$ & $\mathbf{8}$ \\
\hline $\begin{array}{l}\text { VIII. Ser uno de los ejemplos representativos de importantes etapas de la historia de la tierra, } \\
\text { incluyendo testimonios de la vida, procesos geológicos creadores de formas geológicas o } \\
\text { características geomórficas o fisiográficas significativas. }\end{array}$ & $\mathbf{3}$ \\
\hline $\begin{array}{l}\text { IX. Ser uno de los ejemplos eminentes de procesos ecológicos y biológicos en el curso de la } \\
\text { evolución de los ecosistemas. }\end{array}$ & $\mathbf{3}$ \\
\hline $\begin{array}{l}\text { X. Contener los hábitats naturales más representativos y más importantes para la conservación } \\
\text { de la biodiversidad, incluyendo aquellos que contienen especies amenazadas de destacado valor } \\
\text { universal desde el punto de vista de la ciencia y el conservacionismo. }\end{array}$ & $\mathbf{3}$ \\
\hline
\end{tabular}

Fuente: World Heritage Center [www.whc.org] y elaboración propia.

\section{EL RECONOCIMIENTO PATRIMONIAL DEL PAISAJE EN ESPAÑA}

\section{III.1. La dimensión paisajística de los bienes patrimoniales en España}

La reflexión sobre los lugares españoles susceptibles de integrar la Lista como paisajes culturales debe partir de ámbitos cuyo valor patrimonial ya haya sido institucionalmente reconocido. Ello no es tarea fácil dada la dispersión de normas existente (Ley de Patrimonio Histórico Español, Ley del Patrimonio Natural y la Biodiversidad...); por la profusión de administraciones implicadas (cultura, medio ambiente, agricultura, ordenación del territorio...); y, sobre todo, por la duplicidad normativa e institucional entre el Estado central y los gobiernos autonómicos, que son los que poseen estas competencias. Un primer filtro aconseja deslindar las normas y administraciones específicamente patrimoniales del resto. Las referencias básicas son la Ley 16/1985 de Patrimonio Histórico Español y la Ley 42/2007 del 
Patrimonio Natural y la Biodiversidad que, sometidas a un segundo filtro, permiten seleccionar entre los bienes de interés cultural (bic) y los espacios naturales protegidos (enp), y sus denominaciones autonómicas equivalentes, aquellos que, a priori, podrían ser considerados paisajes patrimoniales.

Del elenco de figuras contenidas en la Ley del Patrimonio Natural y la Biodiversidad y sus homólogas autonómicas ${ }^{5}$, sólo los parques (nacionales, naturales, rurales y/o regionales, dependiendo de sus concreciones autonómicas) y los paisajes protegidos podrían constituir paisajes patrimoniales. Otras figuras con un calado territorial importante, como las reservas y los parajes naturales, no contienen entre sus fines la contemplación o el uso público y, además, excluyen la presencia humana, por lo que en principio no constituirían paisajes patrimoniales. Otro tanto cabe señalar de los monumentos naturales, mayoritariamente representados por elementos puntuales (un árbol, un roquedal, una fuente...), que pueden ser hitos paisajísticos pero que en sí mismos no son paisajes. No obstante, un análisis pormenorizado de los monumentos naturales aconsejaría considerar algunos como paisajes patrimoniales, especialmente aquellos con una impronta cultural importante y una extensión espacial considerable (Las Médulas; Palancales y Tierra Muerta; Camí dels Pelegrins de les Useres), y otros menos extensos pero igualmente relevantes por su impronta cultural (Cerro del Hierro; Corrales de Rota...).

En conjunto, la red española de espacios naturales protegidos está compuesta por más de 1.700 lugares que superan los 6,5 millones de hectáreas (Europarc, 2012). Aquellos susceptibles de constituir paisajes patrimoniales serían: los 14 parques nacionales (cerca de 350.000 ha); 311 lugares entre parques naturales, parques rurales y/o parques regionales (en torno a $3.400 .000 \mathrm{ha}$ ); y 57 paisajes protegidos (alrededor de $158.000 \mathrm{ha}$ ). A ellos hay que sumar los espacios declarados por programas internacionales, que en buena parte se superponen a los anteriores: 39 reservas de la biosfera y los territorios de la Red Natura (1.446 LICs y 595 ZEPAs, con una superficie de más de $137.000 \mathrm{~km}^{2}$ ).

En la Ley de Patrimonio Histórico Español, sólo la figura de monumento carecería de la proyección espacial suficiente para ser paisajes patrimoniales; lo que no impide, al igual que se ha señalado respecto a los monumentos naturales, que se trate en muchos casos de hitos paisajísticos muy relevantes. Todas las demás figuras son susceptibles de ser consideradas como tales: conjuntos históricos (909), sitios históricos (285), zonas arqueológicas (982) y jardines históricos $(99)^{6}$; entre todos ascienden a 2.275 bienes (Ministerio de Educación, Cultura y Deporte, en línea). Es importante recalcar la relevancia territorial y paisajística de buena parte de los bienes de interés cultural, contraria a la visión puntual que a menudo se tiene de ellos, particularmente por las administraciones encargadas de su salvaguarda y gestión, que ni siquiera creen relevante incluir en las estadísticas sus superficies ${ }^{7}$. Esto

5 La Ley del Patrimonio Natural y la Biodiversidad diferencia cinco figuras de protección (parques, reservas naturales, áreas marinas protegidas, monumentos naturales y paisajes protegidos), y otra adicional representada por los lugares reconocidos por las normas internacionales.

6 A ellas habría que añadir otras figuras de protección contenidas en las normas autonómicas como los lugares de interés etnológico, los lugares de interés industrial, las zonas patrimoniales, etcétera.

7 Las bases de datos del Ministerio de Educación, Cultura y Deporte y/o de los gobiernos autonómicos no contienen información sobre superficies, por lo que la determinación de la extensión los bienes de interés cultural con significación paisajística requeriría un análisis pormenorizado de cada expediente de declaración, lo que supera los objetivos de este artículo. 
último supone un tratamiento diferente respecto a los espacios naturales protegidos y añade una dificultad adicional para las comparaciones y necesarias agregaciones de dos categorías patrimoniales (natural-cultural) cuya separación es, tal y como se viene argumentando en este trabajo, meramente administrativa y nominativa.

La figura 1 recoge el reconocimiento patrimonial, ambiental y cultural, en España. De ella se colige una gran presencia patrimonial en el territorio: en zonas de montaña, en espacios litorales, en zonas muy urbanizadas... Ello no obsta para que haya áreas con un escaso número de bienes registrados, lo que no siempre debe interpretarse como una carencia de bienes patrimoniales de interés, sino como que, con frecuencia, están a la espera de su reconocimiento por los organismos competentes.

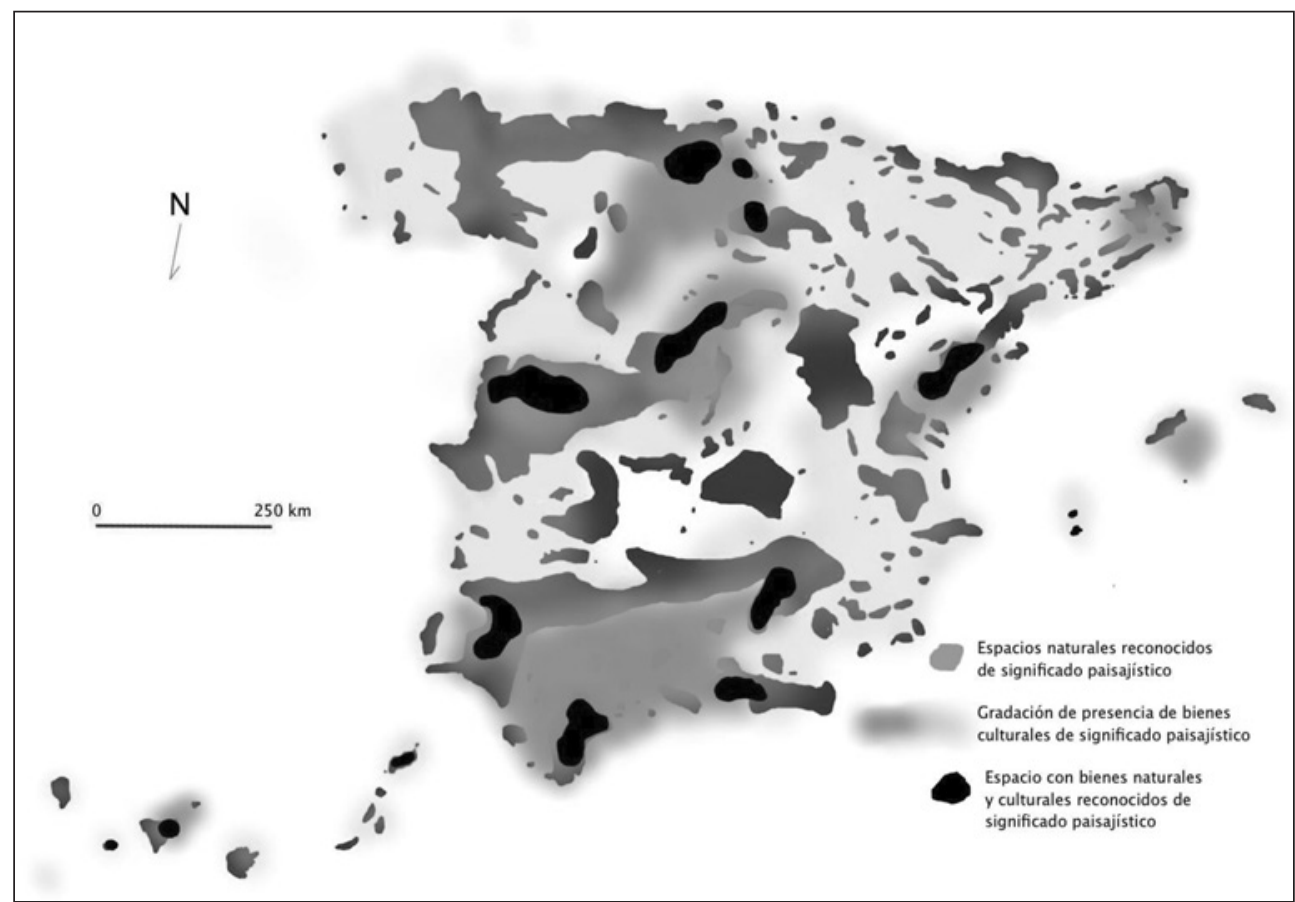

Fuente: Ministerio de Educación, Cultura y Deporte (en línea), Europarc (2012, pp. 30-31) y Elaboración propia.

A partir de la figura 1 pueden identificarse:

- Áreas relativamente poco reconocidas, tanto desde el punto de vista natural como cultural: buena parte de Castilla-La Mancha; occidente de Castilla y León; amplias zonas de Aragón, Galicia...

- Áreas con presencia relativa destacada sólo de bienes naturales: Pirineos, Sierra Morena, Cordillera Cantábrica... 
- Áreas con presencia relativa destacada sólo de bienes culturales: vegas y campiñas del Guadalquivir, Maestrazgo, noreste de Castilla y León...

- Áreas relativamente bien reconocidas, tanto desde el punto de vista natural como cultural: Alcornacales y serranía de Ronda, Guadarrama, Tenerife...

No se trata de asumir que todos los espacios naturales protegidos y bienes de interés cultural deban -o puedan- aspirar al reconocimiento de Unesco, cuestión que, por razones obvias, no sería posible ni deseable-. Además, se es consciente de que hay paisajes sin refrendo institucional que merecerían integrar la Lista. Aun así, la identificación de espacios con reconocimientos patrimoniales de potencial paisajístico es un buen punto de partida para la selección de posibles propuestas de paisajes culturales de Unesco; además, la necesaria elaboración de planes de ordenación de los recursos naturales y planes gestores de uso y gestión de los espacios naturales protegidos o la obligación -sólo parcialmente asumida- de elaborar planes especiales para algunas categorías de bienes culturales prueban, en principio, la capacitación para elaborar planes e instrumentos de preservación de los bienes declarados: dos recursos que Unesco considera básicos en la aceptación de candidaturas.

\section{III.2. España en la Lista del Patrimonio Mundial}

Se ha señalado el peso de España en la Lista; con 44 bienes (tabla 3), sólo es superada por Italia. Este reconocimiento se convierte, en cambio, en una importante cortapisa para la incorporación de nuevos bienes, tal y como se deduce de las prioridades de Unesco; pero existen estrategias para seguir incrementando el número de bienes en dicho listado. Para activarlas es necesario considerar con detalle el complejo proceso que deben seguir los bienes españoles para incorporarse a la Lista, que sería muy distinto si España tuviese menos bienes en ella, si no estuviera en la región Europa y Norteamérica de Unesco o si el carácter de sus bienes no fuese mayoritariamente cultural.

Según se aprecia en la tabla 4, en la que se sintetiza el proceso para la inscripción de bienes en la Lista, el protagonismo y responsabilidad ante Unesco la posee el Estado español, que coordina el proceso desde la fase inicial hasta elevar las propuestas al Comité del Patrimonio Mundial en la fase conclusiva. El Ministerio de Educación, Cultura y Deporte (con diferentes denominaciones en los últimos decenios) ha hecho de intermediario al canalizar a Unesco las candidaturas propuestas por las comunidades autónomas. Una regla no escrita ha pretendido que todas tengan algún bien declarado y este objetivo está bien cubierto, hasta el punto de que sólo las ciudades autónomas de Ceuta y Melilla no poseen ningún bien en la Lista ${ }^{8}$.

8 Una de las razones no explicitadas de por qué no se han tramitado expedientes de estas dos ciudades (que sí aparecen en una Lista Indicativa extra oficial en www.mcu.es/patrimonio/MC/PME/ProcesoCandidaturas.html [6 de marzo de 2013]), es el más que probable rechazo a incorporar bienes de estas ciudades reclamadas por Marruecos. La representación regional en el Comité del Patrimonio Mundial (que se compone de 21 países que rotan) asegura siempre la presencia de algún estado árabe que previsiblemente se opondrá a que bienes de estas dos ciudades terminen engrosando la Lista como bienes españoles. 
Tabla 3

BIENES ESPAÑOLES INSCRITOS EN LA LISTA DEL PATRIMONIO MUNDIAL

\begin{tabular}{|c|c|}
\hline Bien & Tipo \\
\hline Alhambra, Generalife y Albaicín de Granada & Cultural \\
\hline Catedral de Burgos & Cultural \\
\hline Centro histórico de Córdoba & Cultural \\
\hline Monasterio y Sitio de El Escorial & Cultural \\
\hline Obras de Antoni Gaudí & Cultural \\
\hline Centro hco. de Ávila y sus iglesias extramuros & Cultural \\
\hline Santiago de Compostela (centro hco.) & Cultural \\
\hline Centro hco. de Segovia y su acueducto & Cultural \\
\hline Cueva de Altamira y arte rupestre paleolítico del Norte de España & Cultural \\
\hline Monumentos de Oviedo y del Reino de Asturias & Cultural \\
\hline Arquitectura mudéjar de Aragón & Cultural \\
\hline Centro hco. de Cáceres & Cultural \\
\hline Ciudad histórica de Toledo & Cultural \\
\hline Parque Nacional de Garajonay & Natural \\
\hline Catedral, Alcázar y Archivo de Indias en Sevilla & Cultural \\
\hline Centro hco. de Salamanca & Cultural \\
\hline Monasterio de Poblet & Cultural \\
\hline Conjunto arqueológico de Mérida & Cultural \\
\hline El Camino de Santiago de Compostela & Cultural \\
\hline Real Monasterio de Santa María de Guadalupe & Cultural \\
\hline Parque Nacional de Doñana & Natural \\
\hline Ciudad histórica fortificada de Cuenca & Cultural \\
\hline La Lonja de la Seda de Valencia & Cultural \\
\hline Las Médulas & Cultural \\
\hline Monasterios de San Millán de Yuso y de Suso & Cultural \\
\hline Palacio de la Música Catalana y Sant Pau, Barcelona & Cultural \\
\hline Pirineos-Monte Perdido (Paisaje cultural) & Mixto \\
\hline Arte rupestre del arco mediterráneo de la Península Ibérica & Cultural \\
\hline Universidad y centro hco. de Alcalá de Henares & Cultural \\
\hline Ibiza, biodiversidad y cultura & Mixto \\
\hline San Cristóbal de La Laguna & Cultural \\
\hline Conjunto arqueológico de Tarraco & Cultural \\
\hline Iglesias románicas catalanas del Vall de Bohí & Cultural \\
\hline Muralla romana de Lugo & Cultural \\
\hline Palmeral de Elche & Cultural \\
\hline Sitio arqueológico de Atapuerca & Cultural \\
\hline Paisaje cultural de Aranjuez (Paisaje cultural) & Cultural \\
\hline Conjuntos monumentales renacentistas de Úbeda y Baeza & Cultural \\
\hline Puente de Vizcaya & Cultural \\
\hline Parque Nacional del Teide & Natural \\
\hline Torre de Hércules & Cultural \\
\hline Sitios de arte rupestre prehistórico en el Valle del Côa y Siega Verde & Cultural \\
\hline Paisaje cultural de la Serra de Tramuntana (Paisaje cultural) & Cultural \\
\hline Patrimonio del mercurio. Almadén e Idria & Cultural \\
\hline
\end{tabular}

Fuente: Centro del Patrimonio Mundial [http://whc.unesco.org/en/tentativelists/state=es, 6 de marzo de 2013] y elaboración propia. 
Tabla 4

PROCESO PARA INCORPORAR BIENES ESPAÑOLES A LA LISTA DEL PATRIMONIO MUNDIAL

\begin{tabular}{|c|c|}
\hline \multirow[b]{2}{*}{ Fase inicial } & $\begin{array}{l}\text { Cada comunidad autónoma selecciona, por iniciativa propia o canalizando alguna } \\
\text { solicitud local, bienes susceptibles de ser declarados Patrimonio Mundial. }\end{array}$ \\
\hline & $\begin{array}{l}\text { Las propuestas se presentan al Grupo de Trabajo I de Patrimonio Mundial (integrado } \\
\text { por representantes del Ministerio de Educación, Cultura y Deporte y de las áreas de } \\
\text { patrimonio autonómicas). Éste realiza un informe técnico de cada una y lo remite a las } \\
\text { comunidades. }\end{array}$ \\
\hline \multirow{2}{*}{$\begin{array}{l}\text { Fase de } \\
\text { inscripción en la } \\
\text { Lista Indicativa }\end{array}$} & $\begin{array}{l}\text { Cada comunidad presenta al Consejo de Patrimonio Histórico sus propuestas con los } \\
\text { informes técnicos del Grupo de Trabajo. Este consejo es un órgano de coordinación } \\
\text { entre el Ministerio de Educación, Cultura y Deporte y los responsables de cultura de las } \\
\text { comunidades autónomas. }\end{array}$ \\
\hline & $\begin{array}{l}\text { El Consejo del Patrimonio Histórico aprueba las propuestas consensuadas para su } \\
\text { inclusión Lista Indicativa de España y el Ministerio de Educación, Cultura y Deporte las } \\
\text { traslada al Comité del Patrimonio Mundial para su aprobación. }\end{array}$ \\
\hline $\begin{array}{l}\text { Fase de } \\
\text { elaboración del } \\
\text { expediente }\end{array}$ & $\begin{array}{l}\text { La comunidad autónoma elabora el expediente para la declaración. Éste puede ser } \\
\text { elaborado por varias comunidades, caso de ser propuestas interautonómicas (aunque } \\
\text { suele haber una que lidera esta fase); o en colaboración con otros países, caso de ser } \\
\text { una propuesta transnacional (en cuyo caso el protagonismo depende del país del que } \\
\text { surja la propuesta). Las comunidades suelen solicitar la colaboración de consorcios, } \\
\text { ayuntamientos, asociaciones, consultoras, agentes profesionales, entre otros, para la } \\
\text { elaboración de los expedientes. }\end{array}$ \\
\hline \multirow[t]{2}{*}{ Fase conclusiva } & $\begin{array}{l}\text { Finalizado el expediente, se remite al Ministerio de Educación, Cultura y Deportes } \\
\text { que, o sugiere mejoras, o directamente lo eleva al Consejo del Patrimonio Histórico y } \\
\text { éste decide cada año qué expedientes se propondrán para su incorporación a la Lista. } \\
\text { La decisión se conoce a menudo antes de la finalización de los expedientes; sobre todo } \\
\text { cuando el Consejo tiene evidencias de los que se encuentran más avanzados y con calidad } \\
\text { suficiente. De facto, cuando una comunidad anuncia en un Consejo que un expediente se } \\
\text { encuentra avanzado, esta noticia es asumida como una especie de petición de turno para } \\
\text { las próximas propuestas a Unesco. }\end{array}$ \\
\hline & $\begin{array}{l}\text { La remisión del expediente al Comité del Patrimonio Mundial debe observar un preciso } \\
\text { calendario anual. Cuando el Comité se reúne, ya existen valoraciones técnicas sobre los } \\
\text { expedientes de los organismos asesores, fundamentalmente Icomos y Iucn. El Comité } \\
\text { decide si aprueba la declaración; si la devuelve al Estado para realizar modificaciones; si } \\
\text { lo pertinente es una reestructuración general; o si se requeriría una propuesta nueva para } \\
\text { su aceptación. }\end{array}$ \\
\hline
\end{tabular}

Fuente: Ministerio de Educación, Cultura y Deporte (en línea) http://www.mcu.es/patrimonio/MC/PatrimonioMundial/BienesDec/ProcesoCandidaturas.html [6 de marzo de 2013] y elaboración propia.

El Ministerio, a través del Consejo de Patrimonio Histórico, actualiza y pone en orden la Lista Indicativa (tabla 5) según las peticiones de las comunidades autónomas, priorizando aquellas menos representadas y, sobre todo, aquellas con expedientes en las últimas fases de elaboración. En cualquier caso, estar en la Lista Indicativa no significa siempre que exista un interés prioritario por parte del Ministerio o de las comunidades autónomas en resolver estos casos. Dos ejemplos contrapuestos de la misma comunidad: mientras la Ribera Sacra permanece en la Lista Indicativa desde 1996, la Torre de Hércules fue declarada en 2009 sin 
apenas haber pasado por ella. En la Lista Indicativa están presentes todas las comunidades sin excepción (salvo las ciudades autónomas de Ceuta y Melilla por las razones aludidas en la nota 8) y esto demuestra que pesa más el equilibrio entre comunidades para conformar esta lista que los criterios científicos y recomendaciones de Unesco. Sobre esto último, baste señalar que 22 de los 26 bienes de la Lista Indicativa son de carácter cultural, 3 mixtos y sólo 1 natural; cuando España es un país, como ya se ha referido, con muchas cortapisas para incrementar las declaraciones culturales.

Como acción positiva que contrarresta la citada tendencia a la atomización autonómica, debe destacarse el papel del Ministerio en el impulso a candidaturas que estén promovidas por varias comunidades: de los 26 bienes incluidos en la Lista Indicativa, 9 son respaldados por más de una de ellas, 3 son transnacionales y 3 son ampliaciones; vía esta, la de la ampliación, que siempre resulta más sencilla que conseguir una nueva declaración. Sin embargo, tampoco la estrategia de coordinar varias comunidades resulta siempre acorde a los valores del bien: por ejemplo, la ampliación de los caminos de Santiago a los del norte no cuenta con el apoyo de Castilla y León; y, al contrario, ésta es la única comunidad que promueve la candidatura de la Mesta, que atañe a un número muy considerable de comunidades; y lo mismo podría decirse sobre las vías romanas, de las que se produce una duplicidad de propuestas: la Vía de la Plata (promovida por Castilla y León y Extremadura) y las Vías Romanas. Itinerarios del Imperio Romano (promovida por Andalucía, Castilla-La Mancha, Cataluña y la Comunidad Valenciana); etcétera.

El Ministerio maneja criterios de carácter político (las aspiraciones de las comunidades autónomas) y técnicos (las exigencias de Unesco), pero tiene poca iniciativa más allá de coordinar los aspectos reseñados en el párrafo anterior, realizar algunos encuentros de carácter técnico o celebrar el propio Consejo de Patrimonio Histórico. Incluso en relación con los graves problemas que han afectado a algunos bienes españoles ya en la Lista (y que amenazaron con incluir alguno de ellos, como es el caso de Sevilla, en la Lista del Patrimonio en Peligro), el Ministerio ha adoptado un papel secundario, arguyendo que las competencias culturales en España las poseen las comunidades autónomas; aunque, para Unesco, el único interlocutor es el Estado Parte.

Los listados de las tablas 3 y 5 ponen otra vez de manifiesto la preponderancia del tipo cultural sobre el natural y el mixto. Actualmente hay tres paisajes culturales españoles: Aranjuez, Monte Perdido (compartido con Francia) y la Sierra de Tramuntana; aunque otros bienes declarados también podrían ser considerados en esa categoría (Palmeral de Elche, Doñana, Las Médulas...). Algunas ciudades como Granada, Toledo o Córdoba podrían reclasificarse como paisajes urbanos históricos, una nueva categoría asumida por Unesco que plantea la consideración del patrimonio y el paisaje urbanos de forma integrada, más allá de los centros históricos; previsiblemente numerosas ciudades, como ya lo ha hecho Río Janeiro, se incorporarán con esta categoría a la Lista en los próximos años (Unesco, 2011). Alguna candidatura de paisaje cultural ha sido recientemente denegada (Plasencia, Trujillo, Monfragüe: Paisaje Mediterráneo), y otras se están gestando (La Alpujarra) y otras serán presentadas a Unesco próximamente (Valle Salado de Añana). Existe una descoordinación interadministrativa en la preparación de candidaturas, un desconocimiento mutuo de las propuestas y, en casos de denegación, tampoco se difunden suficientemente las causas que los motivan. 
Tabla 5

LISTA INDICATIVA DE ESPAÑAACTUALIZADAA 29 DE ENERO DE 2013

\begin{tabular}{|l|c|}
\hline Bien & Tipo \\
\hline Ribeira Sacra, Lugo y Orense & Cultural \\
\hline Arquitectura de piedra en seco & Cultural \\
\hline Espacio románico del norte de Castilla León y sur de Cantabria & Cultural \\
\hline Fortificaciones abaluartadas fronterizas & Cultural \\
\hline Itinerario cultural de la vid y el vino en los pueblos del Mediterráneo & Cultural \\
\hline Molinos de vela del Mediterráneo & Cultural \\
\hline Monasterio de San Lorenzo Escorial y entorno natural & Cultural \\
\hline Vía de la Plata & Cultural \\
\hline Itinerario Cultural de Francisco Javier (transnacional) & Cultural \\
\hline Conjunto Arqueológico de Ampurias & Cultural \\
\hline Yacimientos de Icnitas de la Península Ibérica (transnacional) & Natural \\
\hline Vertiente Mediterránea de los Pirineos (transnacional) & Mixto \\
\hline Ancares-Somiedo & Mixto \\
\hline Camino del Norte o Camino Primitivo de Santiago (ampliación de El Camino de Santiago) & Cultural \\
\hline Cañadas de La Mesta & Cultural \\
\hline Castillo de Loarre & Cultural \\
\hline Centro Histórico de las Palmas de Gran Canaria & Cultural \\
\hline Patrimonio Histórico del Ferrol de la Ilustración & Cultural \\
\hline Patrimonio Histórico Minero & Cultural \\
\hline Vías romanas. Itinerarios del Imperio Romano & Cultural \\
\hline Plasencia-Monfragüe-Trujillo: Paisaje mediterráneo & Mixto \\
\hline Dólmenes de Antequera & Cultural \\
\hline Catedral de Jaén (ampliación de Conjuntos monumentales renacentistas de Úbeda y Baeza) & Cultural \\
\hline Valle Salado de Añana & Cultural \\
\hline Cultura talayótica en Menorca & Cultural \\
\hline Vino y viñedos de la Rioja y Rioja Alavesa & Cultural \\
\hline
\end{tabular}

Fuente: WHC y elaboración propia [http://whc.unesco.org/en/tentativelists/state=es, consultada el 6 de marzo de 2013]

Aunque son sólo tres, la presencia de paisajes culturales españoles en la Lista es alta si se compara con la de otros países. Así, aunque con un número ligeramente inferior, se sitúa en el rango de los países mejor representados, casi todos europeos (Italia, Reino Unido, Francia, Portugal...). Por esta circunstancia es necesario afinar tanto en los criterios y prioridades de Unesco, como en las diferentes categorías de paisajes patrimoniales para encontrar aquellos menos representados.

Si se proyectan sobre un mapa los bienes de la Lista y los de la Lista indicativa (figura $2^{9}$ ), se confirma el desequilibrio territorial y de carácter (natural, cultural y mixto) de los bie-

9 En el mapa no se incluyen las propuestas inscritas en la Lista Indicativa de Itinerario cultural de La vid y el vino en los pueblos del Mediterráneo ni Las vías romanas. Itinerarios del Imperio Romano, por no ofrecer referencias espaciales que lo permitan. 
nes españoles. Además, las zonas con importante reconocimiento institucional (figura 1) son también los espacios con mayor presencia en la Lista: buena parte de Andalucía, Comunidad de Madrid, La Rioja, Cataluña, etcétera. En la misma línea, aquellas con escaso reconocimiento son también espacios poco presentes en las listas de Unesco; esto es bien perceptible en la zona central de Castilla y León (paradójicamente la comunidad con más bienes en la Lista, aunque estos se ubican en ciudades y territorios periféricos); de Castilla-La Mancha; si se obvian los refugios del Arco Rupestre Mediterráneo, de Aragón y Murcia; etcétera.

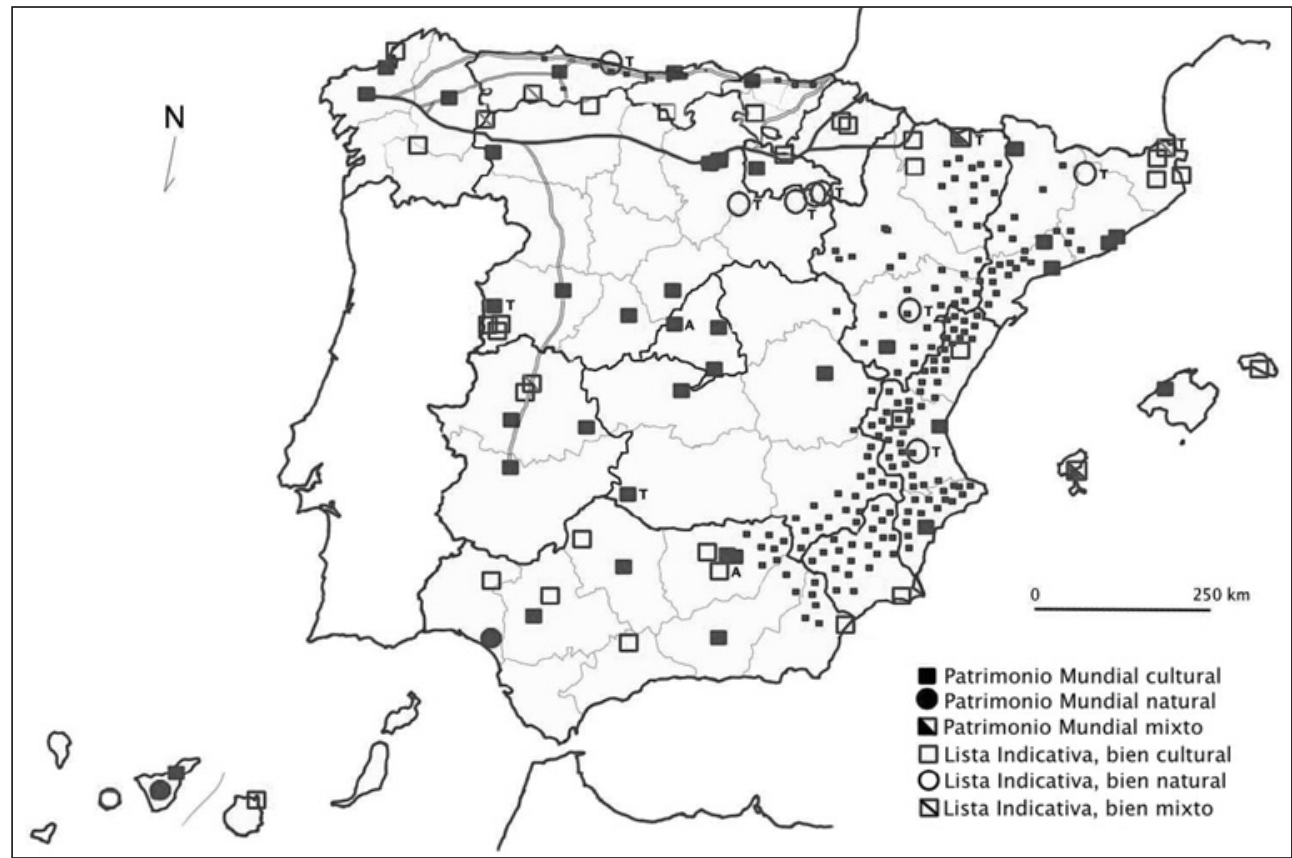

Fuente: WHC y elaboración propia [http://whc.unesco.org/en/tentativelists/state=es, consultada el 6 de marzo de 2013].

Estos desequilibrios hay que relacionarlos con las aspiraciones de las comunidades autónomas que, con frecuencia sometidas a las influencias políticas locales, no saben obviar estas presiones a la hora de reconocer nuevos bienes o, simplemente, no son conscientes de los valores patrimoniales de sus territorios. Ello redunda en una incongruencia de fondo respecto a la filosofía de la Convención de Unesco y también repercute en la escasa legitimación de un patrimonio que podría ser un importante factor de desarrollo, especialmente en las escalas locales.

En la lectura del mapa ha de tenerse en cuenta, además, que la declaración del Arco Rupestre Mediterráneo (y en menor medida la Cueva de Altamira y arte rupestre paleolítico del norte de España) ofrece una sensación de gran densidad que no es tal; sobre todo teniendo en cuenta el carácter puntual de estos refugios y el gran desconocimiento y difícil acceso de casi todos ellos. 


\section{NUEVOS PAISAJES CULTURALES ESPAÑOLES PARA LA LISTA DEL PATRIMONIO MUNDIAL}

Este artículo ha generado cuatro referentes básicos para la identificación de paisajes españoles susceptibles de ser incluidos en la Lista:

a) Tipología de paisajes patrimoniales que, más allá de la manejada por Unesco, general y con pocos matices, ofrezca argumentos que fortalezcan una posible candidatura española (epígrafe II.1).

b) Preferencias del Comité del Patrimonio Mundial para incluir bienes en la Lista (epígrafe II.2.1).

c) Lugares reconocidos por las normativas patrimoniales españolas con interés paisajístico (epígrafe III.1).

d) Situación española en la Lista del Patrimonio Mundial, en general, y respecto a los paisajes culturales, en particular (epígrafe III.2).

Al cruzar toda la información se establece una primera propuesta, abierta y matizable, de lugares susceptibles de ser reconocidos como paisajes culturales de Unesco (tabla 6).

Como criterio general, se ha buscado la presencia de paisajes representativos de prácticamente todas las categorías de la tabla 1, de manera que se ofrezca a Unesco un referente más generoso que las categorías actualmente en vigor. También se han tenido en cuenta aquellos territorios poco representados en la Lista y en la Lista Indicativa (Paisaje cultural de Lanzarote, El Estrecho Puente Cultural...), de manera que se proponga un mayor equilibrio territorial -que no simplemente un equilibrio entre comunidades autónomas-, cuestión no resuelta hasta el momento por el Consejo de Patrimonio Histórico. Para ello se señalan en la tabla 6 los paisajes que se encuentran a más de $100 \mathrm{~km}$ de cualquiera de los integrados en la Lista. Como criterios que se adecuan a las preferencias de Unesco, se incluyen:

a) Bienes ya reconocidos en la Lista, pero no como paisajes culturales. Se propone una ampliación, que es la acción más factible en relación con la política de Unesco, con un cambio de escala en la protección del bien (la ampliación del centro histórico al paisaje urbano de Córdoba; del Puente de Vizcaya al paisaje cultural de la Ría del Nervión...).

b) Bienes presentes en la Lista Indicativa susceptibles de ser inscritos como paisajes culturales; aunque, como en el caso anterior, alterando su escala actual (la ampliación de la propuesta de los molinos de vela del Mediterráneo a los paisajes del viento ibéricos; la segregación de Ancares-Somiedo en dos: Los Ancares y Brañas-Cultura Vaqueira; o la readecuación de la candidatura de la vertiente mediterránea de los Pirineos al paisaje del Ampurdán).

c) Bienes transnacionales (Dehesas y montados; Arribes del Duero...).

d) Bienes compartidos por varias comunidades autónomas (Paisaje del bocage; Estructuras en piedra seca...).

e) Bienes que respondan a criterios poco presentes entre los paisajes culturales de Unesco: criterios I, VII, VIII, IX y X (Cabañeros; Saltos del río Navia...).

f) Bienes que aporten originalidad a los paisajes culturales ya reconocidos por Unesco (cultura castreña astur-galaica; los tabarquinos en España, Italia y Túnez...). 
Tabla 6

PROPUESTA DE LUGARES SUSCEPTIBLES DE SER INSCRITOS COMO PAISAJES CULTURALES EN LA LISTA DEL PATRIMONIO MUNDIAL

\begin{tabular}{|c|c|c|c|c|c|c|c|c|c|c|}
\hline Categorías & Tipo de paisaje & Paisajes concretos & 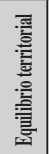 & :誩 & 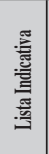 & 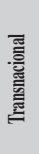 & 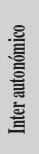 & 雍 & 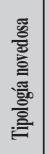 & 嘿 \\
\hline \multirow{13}{*}{$\begin{array}{l}\text { A. Sistemas de } \\
\text { asentamiento }\end{array}$} & \multirow{9}{*}{ A.1 Rurales } & Los Ancares & & & $x$ & & $\mathrm{x}$ & $\mathrm{x}$ & & $* * *$ \\
\hline & & El Caurel & & & & & & $\mathrm{X}$ & & $*$ \\
\hline & & \begin{tabular}{|l|} 
Brañas asturianas-cultura vaqueira \\
\end{tabular} & & & $\mathrm{x}$ & & & $x$ & $\mathrm{x}$ & $* * *$ \\
\hline & & Cultura castreña astur-galaica & & & & & $x$ & $\mathrm{X}$ & $\mathrm{X}$ & $* * *$ \\
\hline & & \begin{tabular}{|l|} 
Isla de La Palma \\
\end{tabular} & $\mathrm{X}$ & & & & & $x$ & & $* *$ \\
\hline & & \begin{tabular}{|l|} 
El Maestrazgo \\
\end{tabular} & & & & & $\mathrm{x}$ & $x$ & & ** \\
\hline & & El Ampurdán & $x$ & & $x$ & & & & & $* *$ \\
\hline & & El Valle de Arán & & & & & & $\mathrm{x}$ & & $*$ \\
\hline & & Cabañeros & & & & & & $\mathrm{X}$ & & * \\
\hline & \multirow{4}{*}{ A.2 Urbanos } & Paisaje de la bahía de Cádiz & & & & & & $\mathrm{x}$ & $\mathrm{x}$ & $* *$ \\
\hline & & Paisaje urbano de Córdoba & & $x$ & & & & & $\mathrm{x}$ & ** \\
\hline & & Paisaje urbano de San Sebastián-Donosti & & & & & & & $\mathrm{x}$ & $*$ \\
\hline & & Paisaje urbano de Barcelona & & $x$ & & & & & $\mathrm{x}$ & ** \\
\hline \multirow{3}{*}{$\begin{array}{c}\text { B. Sistemas de } \\
\text { infraestr. territoriales }\end{array}$} & \multicolumn{10}{|c|}{ B.1 De los transportes y comunicaciones ${ }^{1}$} \\
\hline & \multirow{2}{*}{ B.2 P. De otras infraestr. } & Los paisajes del viento ibéricos & & & $\mathrm{x}$ & $\mathrm{x}$ & $x$ & & & $* * *$ \\
\hline & & \begin{tabular}{|l|} 
Saltos de agua del río Navia \\
\end{tabular} & & & & & & $\mathrm{x}$ & $\mathrm{x}$ & $* *$ \\
\hline \multirow{4}{*}{$\begin{array}{l}\text { C. Sistemas } \\
\text { defensivos }\end{array}$} & \multirow{4}{*}{$\begin{array}{l}\text { C.1 De la defensa y } \\
\text { logística militar }\end{array}$} & La Raya hispano-portuguesa & & $\mathrm{x}$ & $\mathrm{x}$ & $x$ & $\mathrm{x}$ & & $\mathrm{x}$ & $* * *$ \\
\hline & & \begin{tabular}{|l|} 
Fortificaciones abaluartadas con Francia \\
\end{tabular} & & & $\mathrm{x}$ & $x$ & $\mathrm{x}$ & & & $* * *$ \\
\hline & & Ría de Ferrol & & & $\mathrm{x}$ & & & & $\mathrm{x}$ & ** \\
\hline & & Arsenal de Cartagena & & & & & & & $\mathrm{x}$ & * \\
\hline \multirow{11}{*}{$\begin{array}{l}\text { D. Sistemas de } \\
\text { producción }\end{array}$} & \multirow{8}{*}{$\begin{array}{l}\text { D.1 Agrarios y } \\
\text { pesqueros }\end{array}$} & Cult. del agua y minería en Cabo de Gata & $\mathrm{x}$ & & $\mathrm{x}$ & & & $\mathrm{x}$ & & **** \\
\hline & & Vino de Rioja & & & $\mathrm{x}$ & & $\mathrm{x}$ & & & ** \\
\hline & & \begin{tabular}{|l|} 
Vino de Utiel-Requena \\
\end{tabular} & & & & & & & & $*$ \\
\hline & & Cereal de Tierra de Campos & & & & & & & & * \\
\hline & & Paisaje de Bocage & & & & & $\mathrm{x}$ & & & $*$ \\
\hline & & Estructuras en piedra seca & & & $x$ & & $\mathrm{x}$ & & & *** \\
\hline & & \begin{tabular}{|l|} 
Dehesas y montados hispano-portugueses \\
\end{tabular} & & & $\mathrm{x}$ & $x$ & $x$ & & $\mathrm{X}$ & **** \\
\hline & & Los tabarquinos en España, Italia y Túnez ${ }^{2}$ & & & & $x$ & & & $\mathrm{x}$ & $* *$ \\
\hline & \multirow{3}{*}{$\begin{array}{l}\text { D.2 Mineros e } \\
\text { industriales }\end{array}$} & Ría de Bilbao & & $x$ & & & & & & $*$ \\
\hline & & Riotinto-Nerva & & & $\mathrm{x}$ & & & $\mathrm{x}$ & & $* *$ \\
\hline & & Valle salado de Añana & & & $x$ & & & & $\mathrm{x}$ & ** \\
\hline \multirow{4}{*}{$\begin{array}{l}\text { E. Sistemas de } \\
\text { valores simbólicos }\end{array}$} & \multirow{2}{*}{ E.1 Creencias y rituales } & Cultura talayótica & & & $x$ & & & $x$ & & *** \\
\hline & & Paisajes del arte rupestre mediterráneo & & $x$ & & & $x$ & & $\mathrm{x}$ & $* * *$ \\
\hline & E.2 Poder & El Escorial & & $x$ & $\mathrm{x}$ & & $\mathrm{x}$ & & & $* * *$ \\
\hline & E.3 De arte & Lanzarote & $\mathrm{x}$ & & & & & $\mathrm{x}$ & $x$ & ** \\
\hline \multirow{4}{*}{$\begin{array}{l}\text { F. Sistemas de } \\
\text { referentes naturales } \\
\text { connotados }\end{array}$} & \multirow{2}{*}{ F.1 Fluviales y lacustres } & Ribeira Sacra & & & $\mathrm{x}$ & & & $x$ & & ** \\
\hline & & Arribes del Duero hispano-portugueses & & & & $x$ & & $\mathrm{x}$ & $\mathrm{x}$ & $* * *$ \\
\hline & F.2 Relieve & Picos de Europa & & & & & $x$ & $\mathrm{x}$ & $\mathrm{x}$ & $* * *$ \\
\hline & F.3 Tránsito & El Estrecho de Gibraltar puente cultural ${ }^{3}$ & $\mathrm{x}$ & & & $\mathrm{x}$ & & $x$ & $x$ & $* * *$ \\
\hline \multicolumn{11}{|c|}{$\begin{array}{l}* * \text { Candidatura con grandes perspectivas de prosperar. } \\
* * \text { Candidatura con algunas ventajas que pueden convertirla en una propuesta realista. } \\
* \text { Candidatura que, en determinadas circunstancias, podría tener alguna posibilidad de ser incorporada a la Lista. }\end{array}$} \\
\hline \multicolumn{11}{|c|}{$\begin{array}{l}{ }^{1} \text { Los paisajes ligados a itinerarios culturales deben ser enfocados bajo esta categoría patrimonial, menos representada en la Lista incluso que los paisajes culturales. Por esta razón no } \\
\text { se aporta ninguna propuesta en esta tabla. } \\
{ }^{2} \text { La aportación española a esta candidatura sería la isla de Tabarca. } \\
{ }^{3} \text { Ceuta podría ser aceptada en una propuesta que englobase España (Ceuta, bahía de Algeciras, costa del Estrecho hasta Bolonia), Marruecos (Tánger y costa del Estrecho) y Reino } \\
\text { Unido (Gibraltar). }\end{array}$} \\
\hline
\end{tabular}

Fuente: Elaboración propia. 
Del cruce de todos los datos, se infiere la potencialidad de los 38 paisajes identificados para ser integrados en la Lista y constituirse en referentes de gestión para otros paisajes patrimoniales (españoles y extranjeros). En razón de los parámetros utilizados en la tabla 6 se atribuye a cada paisaje su posibilidad de culminar con éxito el proceso: a) con el razonamiento adecuado de sus ventajas actuales (13); b) en virtud de valores y coyunturas que, aprovechados en la defensa del expediente, pueden convertirlos en propuestas realistas (16); o c) en circunstancias especiales o con una argumentación más elaborada (8). No obstante, la inscripción final en la Lista no debe atribuirse sólo a la adaptación objetiva a los criterios de Unesco (que es lo que valora este artículo); existen también influencias políticas en el Comité del Patrimonio Mundial, que serían objeto de otro artículo, y que pueden, o bien declarar un bien con pocas posibilidades, o al contrario, no aprobar uno que cumple todos los requisitos. Por ejemplo, el Paso del Estrecho es, por lo expuesto en la tabla 6 un ámbito susceptible de ser reconocido por Unesco, pero, a las citadas previsibles trabas de la aceptación de Ceuta por Marruecos, habría que añadir las que el propio Estado español arguyese contra el reconocimiento de Gibraltar como bien internacional compartido con el Reino Unido.

\section{CONCLUSIONES}

Desde hace algunos decenios se confirma la emergencia de todo lo relacionado con el paisaje, en general, y con el paisaje patrimonial, en particular. La figura de paisaje cultural de Unesco es un referente internacional de ese interés que no siempre ha estado acompañado del necesario debate sobre qué son los paisajes culturales y los paisajes patrimoniales. En este artículo se ha defendido desde el punto de vista conceptual que la expresión paisaje cultural tiene carácter redundante; puesto que todo paisaje, en cuanto que requiere de la mirada humana, es paisaje cultural y, por la misma razón, se niega la existencia de paisajes naturales. Consecuentemente, se aconseja utilizar la expresión paisaje cultural sólo para referirse a esta categoría de Unesco y se prefiere para uso general la expresión paisaje patrimonial; entendiendo como tal aquel que por su carácter identitario, su excepcionalidad y/o representatividad requiere salvaguarda y tutela administrativas.

La actualidad de los paisajes patrimoniales también debe ponerse en relación con los profundos cambios operados en el mundo del patrimonio, tanto en lo que se refiere al objeto de tutela (monumentos, bienes inmateriales...), como a los propósitos de dicha tutela (conservación, contemplación, uso turístico...). La gestión de los bienes culturales está reclamando un cambio de planteamientos, y el territorio y el paisaje ofrecen un marco adecuado y a la altura de uno de los principales retos del patrimonio: convertirse en factor de desarrollo. Trabajar en la protección del paisaje es, en buena medida, trabajar en la protección del patrimonio y en el fomento del desarrollo socioeconómico y cultural de los territorios.

Este artículo se ha interesado por los paisajes incluidos en la Lista de Unesco desde la perspectiva de los paisajes patrimoniales españoles que podrían integrarse en ella. Se ha considerado importante una reflexión previa de por qué seguir proponiendo nuevos bienes a Unesco (cuando no han sido pocos los problemas surgidos durante el último decenio en muchos de los ya inscritos: centro histórico de Salamanca; Catedral, Archivo de Indias y Alcázar en Sevilla; Camino de Santiago, etcétera) y no se renuncia a la posibilidad de engrosar la relación de paisajes culturales españoles refrendados por Unesco, tanto porque paisaje 
cultural es una categoría patrimonial con posibilidades de prosperar ante Unesco para los bienes españoles, como, sobre todo, por la previsible extensión de la protección y sensibilización a otros paisajes patrimoniales de nuestro país.

Se ha planteado una visión heterodoxa pero objetiva de las potencialidades de la figura paisaje cultural a partir de los criterios manejados por Unesco y de los lugares que ya cuentan con algún refrendo patrimonial en España. Ello ha exigido un análisis que demuestra el complejo proceso que las administraciones españolas implicadas deben seguir para incorporar paisajes a la Lista. Este proceso está sometido, con frecuencia, no a aspectos conceptuales o técnicos, sino a las presiones políticas de las comunidades autónomas (a su vez presionadas por instituciones locales). Sólo así se explica que se mantengan bienes en la Lista Indicativa con escasas probabilidades de ser declarados (centro histórico de Las Palmas de Gran Canaria o Vertiente Mediterránea de los Pirineos, por ejemplo).

El análisis de los lugares españoles en la Lista confirma la muy mayoritaria presencia de bienes culturales, frente a naturales y mixtos. Esto también proporciona algunas claves para prever qué candidaturas tienen más posibilidades de prosperar. La simplicidad y escasa operatividad de las categorías de Unesco han llevado a utilizar una clasificación de paisajes patrimoniales centrada en la triple consideración del espacio que sustenta a todo paisaje: el espacio como sistema territorial, como sistema productivo y como sistema de valores simbólicos.

Respecto a los actores españoles involucrados en las fases del proceso de gestación, preparación y elevación de candidaturas, y sin que ello suponga menosprecio de los logros alcanzados, que no son pocos a juzgar por la presencia española en la Lista, se identifican las siguientes disfunciones:

- El Estado español, en la aceptación de las candidaturas para su inclusión en la Lista Indicativa, a menudo se deja llevar más por el equilibrio territorial entre comunidades autónomas que por criterios científicos o por recomendaciones de Unesco. Es importante que se opte por un equilibrio en el territorio más que por un equilibrio interautonómico.

- Desde la perspectiva de las comunidades autónomas, la inclusión de bienes situados en sus territorios en la Lista es concebida como un reconocimiento que proporciona prestigio y que, sobre todo, regenera la capacidad de atracción turística.

- Existe una falta de coordinación entre las administraciones implicadas que redunda en una dispersión y desconocimiento de las candidaturas y en una merma del aprendizaje colectivo y de las posibilidades de culminar con éxito un proceso que es complejo y oneroso.

En razón de todo ello, urge avanzar hacia la coordinación interadministrativa y hacia la racionalización de las candidaturas que permitan establecer prioridades estratégicas y baremen objetivamente las posibilidades de éxito. A tal fin, este artículo propone una serie de criterios para la identificación y selección de paisajes patrimoniales españoles susceptibles de ser elevados a Unesco:

- Paisajes patrimoniales resaltados en la literatura científica (paisajes agrarios en sus distintas tipologías -viñedos, silvopastoriles, regadíos históricos...-; paisajes urbanos históricos...). 
- Lugares ya reconocidos por la Ley de Patrimonio Histórico Español o por la Ley de Patrimonio Natural y de la Biodiversidad y sus homólogas autonómicas; y/o que cuentan con un reconocimiento patrimonial de rango internacional (Red Natura, Reserva de la Biosfera...).

- Lugares representativos de distintos tipos de paisajes patrimoniales, según su consideración por Unesco y, sobre todo, respecto a las nuevas taxonomías de paisajes patrimoniales planteadas en este artículo.

Como procedimiento para selección de los paisajes patrimoniales susceptibles de ser elevados a Unesco se emplean los criterios que siguen:

- Como criterio general y de fondo se ha buscado la presencia de paisajes representativos de todas las categorías patrimoniales previamente establecidas.

- Se ha atendido a aquellos paisajes con más posibilidades de prosperar, entre los que se encuentran: aquellos peor representados a nivel nacional entre las categorías de Unesco (paisajes naturales y mixtos); aquellos incluidos en la Lista Indicativa; aquellos ya reconocidos en otras categorías, de manera que la figura de paisaje cultural implique una ampliación o reconsideración de bienes previamente declarados; y aquellos que disponen de planes y programas de gestión (PORN y PGRUG, planes especiales...).

- También se ha buscado un reparto equitativo entre comunidades autónomas y territorios, sobre todo teniendo en cuenta distintas categorías espaciales (sierras, litorales, llanuras interiores...).

Con el fin de ejemplificar todo ello se ha identificado un total de 38 paisajes culturales susceptibles de ser integrados en la Lista. No se trata de una propuesta exhaustiva y/o cerrada, cuyo planteamiento no sería posible ni deseable realizar desde un artículo científico. Aun así, los paisajes seleccionados constituyen un buen punto de partida para la reflexión y determinación de estrategias que puedan ser desarrolladas por el Estado y las comunidades autónomas a partir del Consejo Español de Patrimonio. Éstas deberán contar con el Plan Nacional de Paisajes del Instituto Español del Patrimonio Cultural y con instituciones y organizaciones locales interesadas; de forma que, de un lado, las nuevas propuestas de paisajes culturales a Unesco estén coordinadas y, de otro, que el acerbo conceptual y metodológico sobre paisajes patrimoniales sea aplicado a todas las políticas que tienen incidencia en ellos, de forma que estos paisajes coadyuven a la obtención de desarrollos territoriales más coherentes, competitivos y justos.

\section{BIBLIOGRAFÍA Y DOCUMENTACIÓN DIGITAL}

BRIFFAUD, S. y BROCHOT, A. (en línea, original de 2010, Eds.): Paysages d'exception, paysages au quotidien. Une analyse comparative de sites viticoles européens du Patrimoine mondial. Rapport de recherche remis au ministère de l'Écologie, de l'Énergie, du Développement durable et de la Mer, disponible en http://paysage-developpementdurable.fr/IMG/pdf/rf_briffaud1.pdf [14 de abril de 2013] 
CASTILLO RUÍZ, J. (2009): «La dimensión territorial del patrimonio histórico. Caracterización y dimensiones» en Patrimonio histórico y desarrollo territorial (Castillo, J., Cejudo, E. y Ortega, A., Eds.). Sevilla, Universidad Internacional de Andalucía, 27-48.

CONSEJO DE EUROPA (en línea, original de 2000): Convenio Europeo del Paisaje. Florencia, Consejo de Europa, disponible en www.coe.int/t/dg4/cultureheritage/heritage/ landscape/ versionsconvention/spanish.pdf [3 de abril de 2013]

EUROPARC (2012): Anuario 2011 del estado de las áreas protegidas en España. Madrid, Europarc-España.

FOWLER, P.J. (2003): World Heritage Cultural Landscapes, 1992-2002. París, Unesco. Disponible en unesdoc.unesco.org/images/0013/001331/133121e.pdf [22 de marzo de 2013]

HERMOSILLA, J. (2010, Ed.): Los regadios históricos españoles. Paisajes culturales, paisajes sostenibles. Madrid. Ministerio de Agricultura y Medio Rural y Marino.

LUENGO AÑón, A. y MECHTILD, R. (2012): Paisajes cultural del Patrimonio Mundial, Elche, Ayuntamiento.

MADERUELO, J. (2005): El paisaje. Génesis de un concepto. Madrid, Abada.

MARTINEZ DE PISÓN, E. (2003): «Significado cultural del paisaje», en Les estétiques del paisatge. I Seminari Internacional sobre Paisatge. Barcelona, Consorcio Iniversita Internaciona Menéndez Pelayo de Barcelona. Disponible en www.coac.net/ofpaisatge/ content/2003/2003_eduardo_martinez.pdf [4 de abril de 2013]

MATA OLMO, R. (2008): «El paisaje, patrimonio y recurso para el desarrollo territorial sostenible. Conocimiento y acción pública», Arbor, Ciencia, Pensamiento y Cultural, $\mathrm{n}^{\circ}$ 729, 155-172. Disponible en arbor.revistas.csic.es/index.php/arbor/article/view/168/168 [14 de abril de 2013]

MATA OLMO, R y FERNÁNDEZ, S. (2010): «Paisajes y patrimonios culturales del agua. La salvaguarda del valor patrimonial de los regadíos tradicionales». Scripta Nova, vol. $\mathrm{XIV}, \mathrm{n}^{\circ}$ 337. Disponible en www.ub.edu/geocrit/sn-norm.htm [14 de abril de 2013]

MINISTERIO DE EDUCACIÓN, CULTURA Y DEPORTE (en línea): Consulta a la base de datos de bienes [de interés cultural] inmuebles. Disponible en www.mcu.es/bienes/ cargarFiltroBienes Inmuebles.do?layout=bienesInmuebles\&cache=init\&language=es [19 de marzo de 2013].

ORESZCZYN, S. y LANE, A. (2000): «The meaning of hedgerows in the English landscape: Different stakeholder perspectives and the implications for future hedge management». Journal of Environmental Planning and Management, $\mathrm{n}^{\circ}$ 60, 101-118.

PECSRL (2010): «The Permanent European Conference for the Study of the Rural Landscape. 24th session». Living in landscapes: knowledge, practice, imagination, 23-27 agosto 2010, Riga, PECSRL.

RIESCO CHUECA, P. (2003): «Estéticas privadas y estéticas públicas en la producción y consumo del paisaje rural», en Territorio y patrimonio: los paisajes andaluces (Fernández, J., Roldán, R. y Zoido, F., Coords.). Granada, Instituto Andaluz de Patrimonio Histórico, 58-75.

RODRIGO CÁMARA, J.M. et al. (2012): «Registro de paisajes de interés cultural de Andalucía. Criterios y metodología», Revista Ph-Instituto Andaluz del Patrimonio Histórico, $n^{\circ} 81,64-75$.

SILVA PÉREZ, R. (2010) «La dehesa vista como paisaje cultural. Fisonomías, funcionalidades y dinámicas históricas». Ería, nº 82, 143-157. 
SITTE, C. (1965; ed. original de 1889): City planning according to artistic principles. Nueva York, Random House.

TUAN, Y.F. (2003): Escapismo. Formas de evasión en el mundo actual. Barcelona, Península.

UNESCO (en línea, original de 1962): Recomendación relativa a la protección de la belleza y el carácter de los lugares, París, Unesco. Disponible en http://portal.unesco.org/es/ ev.php-URL_ID=13067\&URL_DO=DO_TOPIC\&URL_SECTION=201.html [21 de abril de 2013]

UNESCO (en línea, 2011): Recomendación sobre el paisaje urbano histórico, con un glosario de definiciones. París, Unesco. Disponible en http://portal.unesco.org/es/ev.phpURL_ID=48857\&URL_DO=DO_TOPIC\&URL_SECTION=201.html [14 de abril de 2013]

VENEGAS MORENO, C. y RODRÍGUEZ RODRÍGUEZ, J. (2002): «Valoración de los paisajes monumentales. Una propuesta metodológica para la integración paisajística de los conjuntos históricos», en VENEGAS, C., y ZOIDO, F. (COORD.) (2002): Paisaje y Ordenación del Territorio. Sevilla, Consejería de Obras Públicas y Transportes Junta de Andalucía, pp. 153-165.

WORLD HERITAGE COMMITEE (en línea): The Operational Guidelines for the Implementation of the World Heritage Convention. Disponible en whc.unesco.org/en/guidelines/ [12 de marzo de 2013] 